\title{
The Relationship of Tourists' Loyalty with Individuals' Normative Beliefs and Tourism Experience of Ecotourism
}

\author{
Maryam Anahid, Farzad Sattari Ardabili* \\ Department of Management, Ardabil Branch, Islamic Azad University, Ardabil, Iran
}

\begin{abstract}
Keywords:

Tourists' Loyalty, Tourists'

Experience, Tourists'

Normative Beliefs

\section{Received}

27September 2017

Received in revised form

28 January 2018

Accepted

08 February 2018

Correspondence:

sattari.farzad@gmail.com

In this study, the effect of normative beliefs and tourists' experience of travelling to different places on their loyalty to the destination is investigated. In this regard, 150 questionnaires were randomly collected from tourists who had travelled to Ardabil in a 20 -day period in the summer of 2016. First, confirmatory factor analysis was conducted on variables. The results of regression test indicated that there is a significant correlation between tourists' previous experience and their normative beliefs and loyalty to the destination. The correlation between these variables is respectively equal to 0.24 and 0.25 . Furthermore, the variables of normative beliefs and tourists' previous experience can predict the changes of tourists' loyalty to the destination at a rate of 0.20 and 0.21 , respectively. These results can help tourism activists to attempt to create mutual feeling and change tourists' normative beliefs when offering services. Moreover, further study to separate the type of norms and their different effect can help to improve services and tourists' experience.
\end{abstract}

(C)AIMI Journals

\section{Introduction}

The effect of tourism in the economic growth of countries and local tourism destinations has been confirmed in every sense. Therefore, an increasing competition has been launched between different countries and destinations. Attracting more tourists, especially in tourism destinations with no particular industrial productions or limited and even a single income source such as oil sale can have a considerable effect on their development in the long term. 
Tourism destinations as well as the picture of tourism places and the process of choosing the destination are the most important part of tourism industry. The behavior of hosts will give visitors the satisfaction to revisit that place. Intention to revisit is due largely to visitors' satisfaction from the destination rather than the process of making decision to revisit the destination. Some independent variables including the quality of received behavior during the trip, satisfaction after purchase, and the excellent nature of the destination can encourage visitors to revisit that place.

Tourists are categorized into two groups: First, those who have travelled to a particular destination for the first time; and second, those who travel to that destination several times. Tourists of the second group and some tourists who have visited the desired destination have high expectations of that place. These expectations are created according to previous travel experience, advertisements, and other people's encouragement. The quality of services and facilities as well as the received and perceived values has a direct effect on trip quality, tourism experience, and tourists' demand level in the future (Uysal \& Williams, 2003).

Experimental researches indicate the positive effect and feedback in tourists' future decisions and their behavior. Therefore, received values, quality, and tourists' satisfaction can predict tourists' future behavioral decisions (Baker \& Crompton, 2000).

Generally, this research attempts to study the effect of tourists' experience of scenery on their decision to revisit those places. Therefore, first, we search for the dimensions of tourism destination attractions according to tourists' priorities in Ardabil City. Then, we study the direct and indirect effects of tourists' experience on their loyalty to the tourism destination through their normative beliefs. Personal normative beliefs in the model of this research are used to study the effect of visitors' personal reasoning on their decision-making to choose the tourism destination.

\section{The Literature Review}

The increasing growth of tourism industry and competition for it at the global level have posed new challenges to destination marketing, thus tourism destinations search for more effective marketing strategies. A successful marketing strategy must not only focus on attracting new customers, but also develop the current customers' loyalty.

Stylos, Vassiliadis, Bellou, and Andronikidis (2016) conducted a research and according to their findings, destination images, holistic images, and personal normative beliefs have a positive and significant effect on predicting the intention to revisit a destination.

Findings and recommendations by Hughes, Wang, and Shu (2015) have indicated that symbolic attractions, activities in the nature, and photography are the special attractions of tourism market in Australia for Chinese university students who live in this country. Moreover, the Internet and word-of-mouth advertisements are the most important information sources, while distance, costs, and time are the most essential deterrents to travelling (Hughes et al., 2015).

\section{Research Question}

The main question of this research is as following: 
- Is there any relationship between the type of tourists' experience in Ardabil City as well as their normative beliefs and their loyalty to the destination (Ardabil City)?

\section{Method}

Open questionnaires of this research were randomly distributed among 460 tourists in Ardabil City during August and September 2016. In order to domesticate the first part of the questionnaire about the visitors' experience, some parts of the questionnaire were amended, translated, and finalized according to the viewpoints of 8 tourism specialists and a test sample selected from 21 tour samples in Ardabil. The writers, then, interviewed the residents in the hotels of Ardabil. Following this, 150 questionnaires were completed and analyzed. The process of completing the questionnaire lasted about 15 minutes for each visitor. Receiving reward (pool ticket) was used as motivation.

\section{Measurement Tools}

\section{Tourism Experience}

For the questions of tourism experience, the summarized version of Picker Patient Experience Questionnaire (Jenikson, Coutler, \& Bruster, 2002) was used. This questionnaire questions the different dimensions of experience that tourists gain when they travel to different places. However, some of its scales cannot be measured in some parts of the world. A sample of this questionnaire has been used in a research conducted by Hughes et al. (2015). Some of the questions of this questionnaire have been deleted or changed, so that it contains the experience that a tourist can gain in Ardabil. For example, the experience of walking on the beach was changed to the experience of walking along the river or touching animals was deleted, since it is not offered in the experience of travelling to Ardabil. The final version of this part includes 15 types of tourism experience in Ardabil. A sample of its dimensions includes admiring the scenery such as Heyran and Sabalan Mountain; visiting ancient monuments including Sheikh Safi al-Din Khanegah and Shrine Ensemble; shopping at shopping centers and handicrafts; going to parks and human-made recreation facilities, namely Shorabil and Alvars; serving regional cuisine such as Ash-e doogh and Halva siah; swimming in spas; visiting the citizens; discovering scenery; learning about the traditional culture of Ardabil; and visiting museums like Ardabil Anthropology Museum and Khataei Museum (Hughes et al., 2015).

Respondents choose their answers between 1 (Very Bad) to 5 (Very Good) according to their preferences.

\section{Normative Beliefs}

To measure people's normative beliefs, a three-question questionnaire was applied. This questionnaire is derived from researches conducted by Triandis (1977), Valois, Desharnais, and Godin (1988), and Huitt (1999). These questions have been tested in various researches and its content validity has been confirmed in the research conducted by Stylos et al. (2016). The answers to the questions of this questionnaire have been categorized according to Likert Scale from 1 (Strongly Disagree) to 7 (Strongly Agree). 


\section{Loyalty to the Destination}

In tourism texts, satisfaction from trip experience plays a role in loyalty to the destination. Tourist's loyalty to the destination reflects upon their tendency to revisit there and recommend it to other people. Tourist's positive experience of services, goods, and other offered sources in the destination motivates them to revisit there and creates positive wordof-mouth effects on friends and other acquaintances (Ruzzier \& Chernatony, 2010). McMullan (2005) measured loyalty by means of its two dimensions, namely behavioral loyalty and attitudinal loyalty.

\section{Results}

\section{Sample Profiles}

Sample profiles are listed in Table 1 which shows the demographic characteristics of respondents. Among 150 participants, 48.7\% were female $(n=73)$ and $51.3 \%$ were male $(\mathrm{n}=77)$. The average age of participants was between 30 to 39 years old and a few number of tourists $(4.7 \%)$ were older than 50 .

A small number of participants (about 27\%) were single and most respondents (about 45.3\%) had MA and higher degrees.

Table 1

The Demographic Characteristics of Respondents $(N=167)$

\begin{tabular}{lccc}
\hline Age & Percentage & Education degree & Percentage \\
\hline $20-29$ & 25.3 & Diploma & 27.3 \\
$30-39$ & 42.0 & Associate degree and BA & 26.0 \\
$40-49$ & 28.0 & MA and higher & 45.3 \\
50 and more & 4.7 & & Percentage \\
\hline Marital & Percentage & Gender & 51.3 \\
\hline Single & 27.3 & Male & 48.7 \\
Married & 72.7 & Female & \\
\hline
\end{tabular}

\section{Factor Analysis}

Table 2 indicates a general review of final scales, means, standard deviations, standard errors, and standardized factor loadings of the constructs used in the measurement model.

Table 2

Final Scales, Means, Standard Deviations, and Standardized Factor Loadings of the Constructs Used in the Measurement Model

\begin{tabular}{|c|c|c|c|c|}
\hline Variables & Questions & $\begin{array}{l}\text { Factor } \\
\text { Loadings }\end{array}$ & Mean & $\begin{array}{l}\text { Standard } \\
\text { Error }\end{array}$ \\
\hline \multirow{4}{*}{$\begin{array}{l}\text { Loyalty to the } \\
\text { destination }\end{array}$} & In future years, I try to revisit this place. & 0.72 & 3.71 & 0.07 \\
\hline & After the trip experience, I think I will revisit this place. & 0.81 & 3.81 & 0.07 \\
\hline & I encourage my family and friends to travel. & 0.77 & 3.64 & 0.08 \\
\hline & If someone asks my advice, I will recommend this place to them. & 0.65 & 3.74 & 0.06 \\
\hline \multirow{3}{*}{$\begin{array}{l}\text { Motivational } \\
\text { beliefs }\end{array}$} & Choosing Ardabil as the tourism destination was my personal opinion. & 0.71 & 3.26 & 0.08 \\
\hline & Choosing Ardabil as the tourism destination is an aim that I must follow as a person. & 0.54 & 3.40 & 0.07 \\
\hline & $\begin{array}{l}\text { Choosing Ardabil as the tourism destination requires that I commit myself to it, so } \\
\text { that my need is met. }\end{array}$ & 0.63 & 3.20 & 0.08 \\
\hline \multirow{6}{*}{ Experience } & Ancient monuments such as mosque, castle, etc. & 0.71 & 3.28 & 0.08 \\
\hline & Regional cuisine of Ardabil such as Ash-e doogh, Halva siah etc. & 0.57 & 3.15 & 0.10 \\
\hline & Visiting museums (Ardabil Anthropology Museum, Khataei Museum etc.) & 0.53 & 3.09 & 0.08 \\
\hline & The quality of services offered to tourists by Ardabil Tourism Organization & n.a & - & - \\
\hline & The way the citizens of Ardabil receive guests and tourists & 0.63 & 3.07 & 0.09 \\
\hline & Visiting the citizens and being familiar with their culture & 0.65 & 3.03 & 0.09 \\
\hline
\end{tabular}




$\begin{array}{lccc}\text { Visiting parks and human-made recreation facilities (Shorabil, Alvars, etc.) } & \text { n.a } & - & - \\ \text { Swimming in spas } & 0.52 & 3.44 & 0.09 \\ \text { Scenery (Heyran, Sabalan Mount, etc.) } & 0.53 & 3.34 & 0.10 \\ \text { Shopping at shopping centers and handicrafts } & \text { n.a } & - & -\end{array}$

According to the table of factor analysis (Table 2), all the components are important, however, components with higher than $0.5 \%$ (factor loading value) were selected. Then, questions number 1, 4, 5, 7, 10 were deleted from the list of variable experience. All the components of loyalty to the destination and normative beliefs were confirmed.

The results of correlation test as well as the descriptive indices of variables are presented in Table 3.

The results of correlation test indicate that there is a significant correlation between all three variables at the alpha level of 0.1 . The mean and standard deviation of tourism experience are equal to 3.19 and 0.77 , respectively. This variable has a correlation with normative beliefs and loyalty to the destination (respectively equal to 0.21 and 0.24 ). The highest mean value is related to loyalty to the destination (3.73) and its standard deviation is equal to 0.75 . There is a correlation between loyalty to the destination and normative beliefs equal to 0.25. Cronbach's Coefficient Alpha for experience, normative beliefs, and loyalty to the destination was equal to $0.77,0.70$, and 0.83 , respectively.

Table 3

The Results of Correlation Test on the Variables of the Research and Its Structure

\begin{tabular}{lccccc}
\hline & 1 & 2 & Mean & SD & Alpha \\
\hline Experience & - & & 3.19 & 0.74 & 0.77 \\
PNB & $0.21^{* *}$ & & 3.29 & 0.79 & 0.70 \\
Loyalty & $0.24^{* *}$ & $0.25^{* *}$ & 3.73 & 0.75 & 0.83 \\
\hline *Significance level is 0.05 & & & & &
\end{tabular}

Table 4 exhibits the results of hypothesis test. Hypotheses 1 and 2 indicate the direct effect of tourists' previous experience about Ardabil as a tourism destination on their loyalty to this city.

The results of testing indicate that tourists' previous experience predicts their loyalty to the destination at a rate of 0.21 . The second hypothesis, which studies the effect of normative beliefs on tourists' loyalty to a particular destination, indicated that normative beliefs could predict tourists' loyalty to the destination and revisiting there at a rate of 0.20 .

Table 4

The Regression Coefficient Model of Predicting Tourists' Normative Beliefs and Loyalty

\begin{tabular}{cccccc}
\hline Regression Path & St.RW & S.E & C.R & p & Results \\
\hline Exp $\rightarrow$ Loyalty & 0.21 & 0.07 & 2.72 & 0.00 & Accepted \\
PNB $\rightarrow$ Loyalty & 0.20 & 0.07 & 2.56 & 0.01 & Accepted \\
\hline
\end{tabular}

\section{Conclusion}

The effect of tourism experience on the tendency to loyalty is discussed in this research. Individuals' experience of surroundings forms their tendencies. This experience may be direct or indirect. Individuals tend towards different things according to their own experience or other people's experience. Tourism experience is a way to interact with the world and has various results or effects on human being and their life in terms of both social and mental 
aspects. Loyalty to the place that tourists have travelled to once upon a time is one of these effects (Sepehrpour, 2014). Moreover, tourists' normative beliefs and their experience can affect tourists' loyalty. It is obvious that tourism experience and tourists' belief can have a close relationship with each other. Individuals' normative beliefs mean their true faith in a particular service, place, and brand, which are acquired through experience. Regarding the results of research hypotheses, tourism experience has a direct and significant effect on tourists' loyalty. The results of this research are confirmed in researches conducted by Sepehrpour (2014), ZarghamBorujeni, Ebrahimi, and Mirfakhreddini (2013), Rafati \& Mirabi (2015), and Chi and Qu (2008). Due to rich natural resources and historical record of cultural heritage, Ardabil Province has the potential for tourism. This province is capable of being a large tourism area and meeting tourists' different needs, so that tourists will be visually, physically, emotionally, and socially satisfied and the area will develop. A number of questions are raised here. How much has Ardabil Province prepared the grounds for attracting and providing tourists' loyalty from organizational and environmental perspectives? Have organizations related to tourism taken any steps to support tourists? Are tourists provided with any facilities when they visit natural and ancient areas? What percent of tourists have travelled to the area for the second and third times? These questions must be answered in order to reach tourism advantages. According to the results of this research, the repetition of travelling to Ardabil or tourists' loyalty requires enhancing tourists' experience and normative beliefs. This fact indicates that tourists' good experience of trip and services offered by the destination are of great importance. These items have been referred to as tourists' loyalty in the present study. Therefore, attempting to provide appropriate services is more important than advertising on television, radio, satellite, and the Internet. In fact, providing appropriate services plays an effective role in attracting tourists and sensory effect of offering services on tourists can have an important role in returning them to the destination.

\section{References}

Baker, D. A., \& Crompton, J. L. (2000). Quality, satisfaction, and behavioral intentions. Annals of Tourism Research, 27(3), 785-804.

Chi, C. G. Q., \& Qu, H. (2008). Examining the structural relationships of destination image, tourist satisfaction and destination loyalty: An integrated approach. Tourism Management, 29(4), 624-636.

Hughes, K., Wang, J., \& Shu, M. (2015). Exploring the travel patterns, preferences, and recommendations of Chinese university students living in Australia. Journal of Hospitality \& Tourism Management, 23, 12-22.

Huitt, W. (1995). Success in the information age: A paradigm shift. Valdosta State University. Valdosta, Georgia. November, 6.

Jenkinson, C., Coulter, A., \& Bruster, S. (2002). The picker patient experience questionnaire: Development and validation using data from in-patient surveys in five countries. International Journal for Quality in Health Care, 14(5), 353-358.

McMullan, R. (2005). A multiple-item scale for measuring customer loyalty development. Journal of Services Marketing, 19(7), 470-481.

Rafati, V., \& Mirabi, V. (2015). The effect of experience, image, satisfaction, and trust in brand on loyalty to brand among customers (Case study: Emersun Company). Paper presented at the Second National Conference on Marketing Researches, Tehran, Iran.

Ruzzier, M. K., \& Chernatony, L. (2010). A systematic approach to branding Slovenia. Paper presented at the Sixth Thought Leaders International Conference on Brand Management, Lugano, Univemità della Svizzera italiana.

Sepehrpour, F. (2014). The effect of tourism experience on the tendency to immigration among Iranians (Unpublished master's thesis). University of Science and Culture, Iran. 
Stylos, N., Vassiliadis, C., Bellou, V., \& Andronikidis, A. (2016). Destination images, holistic images, and personal normative beliefs: Predictors of intention to revisit a destination. Tourism Management, 53, 40-60.

Triandis, H. C. (1977). Interpersonal behavior. Monterey, California: Brook/Cole.

Uysal, M., \& Williams, J. A. (2013). Current issues and development in hospitality and tourism satisfaction. London: Routledge.

Valois, P., Desharnais, R., \& Godin, G. (1988). A comparison of the Fishbein and Ajzen and the Triandis attitudinal models for the prediction of exercise intention and behavior. Journal of Behavioral Medicine, 11, 459-472.

ZarghamBorujeni, H., Ebrahimi, M., \& Mirfakhreddini, F. (2013). Evaluating the performance of services offered by hotels with an approach to process balanced scorecard (Case study: Selected hotels of Yazd Province). The Quarterly Journal of Tourism Management Studies, 8(22), 25-50. 